Kenneth J. Mclaughlin is an associate professor in the Department of Economics at Hunter College and the Graduate School of the City University of New York. The author wishes to thank David Lebow, Gil Maduro, Joseph Ritter, Richard Startz, and participants at the Federal Reserve Bank of St. Louis' Twenty-Third Annual Economic Policy Conference, and participants in seminars at Hunter College and the Federal Reserve Banks of Atlanta and New York.

\section{Are Nominal Wage Changes Skewed Away From Wage Cuts?}

\author{
Kenneth J. McLaughlin
}

\section{D)}

eal-wage cuts are much more common

than nominal wage cuts. Why? By

definition, real cuts must be more common if inflation is positive. Yet there might be more to it. Perhaps workers suffer from money illusion. Maybe managers cannot cut pay in nominal terms, but they can cut real wages. As a result, a low-inflation economy might be a high unemployment economy. And moderate inflation might "grease the wheels" of the labor market.

These issues are being addressed in a burgeoning body of literature on wage changes in panel data (M CLaughlin 1994; Lebow, Stockton, and Wascher 1995; Craig 1995; Akerlof, Dickens, and Perry 1996; Card and Hyslop 1997; Kahn 1997; Altonji and Devereux 1997; Crawford and Harrison 1997; and Christofides and Stengos 1998). To detect the existence of downward rigidity of nominal wages, this literature identifies properties of the distribution of wage changes:

- The frequency of wage cuts

- A spike or mass-point of observations with no change in pay

- Skewness

- Thinning of the distribution below zero

- Holes in the distribution around zero
Correlations of these properties with inflation also help to identify skewness away from nominal wage cuts.

Although these papers have much in common, the specific techniques, data sets, and even conclusions vary. With a series of simple cal culations on a single data set, I intend to integrate the main results from this new and exciting area of research to shed light on an important question for macroeconomic policy and economic theory: Are nominal wage changes skewed away from wage cuts? In particular, does downward nominal rigidity censor some wouldbe wage cuts, transforming some wage changes that would be negative into zerowage changes? To answer this question, I document key properties of the distribution of wage changes in panel data. I show that tests based on the familiar skewness coefficient are particularly weak in the presence of fat-tailed distributions, such as the distribution of wage changes, so I introduce symmetrically differenced histograms, a convenient way to detect asymmetries visually. I also apply mean-median differences and sign tests of symmetry to the wage change data.

Evidence of skewness of wage changes is decisive; however, establishing that wage changes are skewed away from wage cuts requires more than evidence of skewness of wage changes. Is downward nominal rigidity the source of the skewness of wage changes, or is the distribution of wage changes more generally skewed? To sort this out, I calculate measures of thinning, a reduction in the frequency of wage change observations below zero (Lebow, Stockton, and Wascher 1995; Card and Hyslop 1997; and Kahn 1997); the calculations do point to the thinning of wage cuts.

A complete explanation also must account for two other features of wage change distributions. First, by focusing on wage changes close to the median, I show that wage changes are skewed right over a range that has nothing to do with 
downward nominal rigidity at zero. This violates the mirror-image assumption of one thinning estimator; consequently, Lebow, Stockton, and Wascher; and Card and Hyslop overestimate the thinning of nominal wage cuts. Second, I show that skewness of wage changes is basically unrelated to inflation; that is, higher inflation does not reduce the impact of any nominal wage rigidity.

I begin by introducing the issues and methods in the context of the literature.

\section{ONE LITERATURE, TWO QUESTIONS}

One can go a long way toward reconciling disparate conclusions in the literature by drawing a single distinction. That is, one must distinguish between the level or frequency of nominal wage cuts and the sensitivity of nominal cuts to downward rigidities. There is a distinct possibility that nominal wage cuts are common and wage changes are skewed away from wage cuts. The first property of nominal wage changes answers the question, "How common are wage cuts in nominal terms?" The second property answers a complementary but distinct question: Is there evidence of downward rigidity reducing the frequency of nominal wage cuts? One could conclude that nominal wage cuts are common and that they would be more common if nominal wages were not

1 Card and Hyslop (1997, pp. 75 76) conjecture that I failed to detect nominally induced asymmetries because I pooled annual distributions of real-wage changes. But pooling the distributions had no bearing on my conclusions. I reported the spike at zero and positive skewness; I also found that wage changes vary closely with inflation, skewness does not vary with inflation, and wage changes of nonunion and nonminimum-wage workers are symmetric (M Laughlin 1994). These findings led me to conclude that there was little evidence of downward nominal wage rigidity. intrayear data from the Survey of Income and Program Participation (SIPP); Card and Hyslop (1997) using the PSID and matched samples from the Current Population Survey (CPS); and Kahn (1997) using the PSID confirms my findings of surprisingly frequent reported wage cuts even for stayers.

Regarding the complementary question of downward rigidity, my analysis was limited to computing (a) the size of the spike at no change in pay and (b) skewness coefficients. I found that an additional 7 percent of the stayers report no change in pay from year to year, and that the distribution of wage changes was skewed to the right, away from wage cuts (M cLaughlin 1994). ${ }^{1}$ Lebow, Stockton, and Wascher; Card and Hyslop; and Kahn also document the spike, al though Card and Hyslop (1997, note 13) find a substantially larger spike by analyzing hourly workers. Some of the spike at zero could be due to variation in interview dates in the PSID. Lebow, Stockton, and Wascher estimate that 1 percentage point of an 8-percentage-point spike is attributable to interviews occurring within a year. They also estimate that an additional 3 percentage points are due to rounding of wage reports. Card and Hyslop (1997, p. 83), on their CPS sample of hourly workers, also estimate that about half of the spike is attributable to rounding errors.

This literature takes a variety of approaches to estimating skewness of wage changes. Using the skewness coefficient, I found that the overall distribution of wage changes is skewed to the right; however, I also reported that the distributions of wage changes of nonunion workers, nonminimum-wage workers, and salaried workers are dead-on symmetric (M CLaughlin 1994, Table 2). Similarly, Lebow, Stockton, and Wascher report small positive skewness coefficients for all stayers, and sizable positive skewness coefficients for hourly workers. (See also Crawford and Harrison (1997) and Christofides and Stengos (1998) for skewness estimates of wage changes in Canadian union contract data.)

The subsequent literature focuses on the complementary question by estimating 
whether nominal wage cuts are too rare; that is, whether the left side of the distribution is too thin below zero (Lebow, Stockton, and Wascher 1995; Card and Hyslop 1997; Kahn 1997). Lebow, Stockton, and Wascher's measure of skewness subtracts the proportion of observations below zero from the proportion above twice the median. Since zero and twice the median are the same distance from the median, this thinness measure would be zero for symmetric distributions and positive for right-skewed distributions. Their skewness measure is 6.8 , so the left tail below zero is about 7 percentage points thinner than its mirror image on the right side of the distribution. Card and Hyslop also assume that the right tail would be the mirror image of the left in the absence of nominal rigidity. For each year, they provide kernel estimates (basically smoothing) of the actual and counterfactual histograms and find a range of thinning from 6 to 14 percentage points, depending on the year. These are in line with Lebow, Stockton, and Wascher's estimate of 10-percentage-point thinning for hourly workers.

By using year-to-year variation in the position of the wage change distribution, Kahn (1997) estimates the extent of nominal rigidities without imposing the mirrorimage assumption. One checks whether bars of the wage-change histogram tend to be shorter in years when those bars lie below zero. For instance, is the third bar below the median shorter in those years when it lies below zero? Kahn's regression estimates, which weight the effects across bars, imply that 9 percent of hourly workers' would-be wage cuts are censored at zero. The only evidence of downward rigidity for salaried workers is early in her sample period (before 1982), but this evidence appears to be dominated by more frequent than expected nominal cuts after 1982.

With the two questions distinguished, the papers in this literature share much in common. Nominal wage cuts are not rare, but there is evidence of a spike at zero, positive or right skew of distribution, and thinning of the distribution below zero. The evidence is much weaker, however, for salaried workers and nonunion workers. Another common feature is that about three-quarters of would-be wage cuts actually occur. Removing downward nominal rigidity would increase the frequency of reported wage cuts of stayers from the observed 17 percent to 22 percent (using Kahn's estimates of thinning) or from 18 percent up to 24 percent (using Lebow, Stockton, and Wascher's estimates of thinning). Even in the CPS sample of hourly wage workers, about three-quarters of the predicted wage cuts appear in the data (Card and Hyslop 1997).

If nominal wages are downwardly rigid, then there should be less skewness and thinning in high inflation periods. The evidence on this important point is mixed. I found that the skewness coefficient is positively correlated with anticipated and unanticipated inflation, which is not consistent with inflation relaxing the impact of nominal wage rigidity (McLaughlin 1994, note 12 ). Lebow, Stockton, and Wascher's (1995) thinness measure is not significantly correlated with inflation on their sample of all stayers, although the correlation is negative for hourly workers. On the CPS sample of hourly workers, Card and Hyslop (1997) find less thinning in high inflation periods. Hence any evidence of inflation reducing the impact of nominal wage rigidity is limited to hourly workers.

\section{But Are Wage Cuts Common?}

Perhaps survey reports of wages are riddled with error and the appearance of nominal wage cuts is illusory. The wage variables in these surveys refer to straighttime pay on the main job during the survey week or the most recent pay period; wages are not generated by dividing annual earnings last year by annual hours worked. Indeed, for the SIPP data on hourly workers, a respondent is asked what the hourly wage rate was on his last pay stub (Craig 1995). But the role of measurement error in inflating reported wage cuts deserves scrutiny.

To identify the frequency of true wage cuts, I estimated the variance of the measurement error component and applied a mean-preserving compression to correct 
the distribution of wage changes (M CLaughlin 1994). I took three very different tacks to estimate the error variance:

- First, I drew reliability measures of wage change variables from validation studies (Bound and Krueger 1991; Bound, Brown, Duncan, and Rodgers 1994).

- Second, I used the frequency of reported nominal wage cuts of minimum-wage workers, which were assumed to be due to measurement error.

- Third, I associated measurement error with the stationary component of wage change residuals, and the random walk component of wages was classified as true variation.

The three methods pointed to a single conclusion. Although significant measurement error is present in wage changes, wage cuts remain fairly common in the corrected distributions. ${ }^{2}$ In particular, my most conservative measurement error correction reduced the frequency of nominal wage cuts from 17 percent to 12 percent.

Suspicious that measurement error is the source of reported nominal wage cuts, Akerlof, Dickens, and Perry (1996) asked respondents in a Washington, D.C., telephone survey whether they had experienced wage cuts during the previous year. That is, rather than differencing wage responses across years, Akerlof, Dickens, and Perry asked a single qualitative question directly. About 3 percent of the stayers reported cuts in base pay. Akerlof, Dickens, and Perry conclude that the frequency of wage cuts in panel data is an artifact of measurement error. It is well known, however, that survey respondents under report embarrassing personal information, so this survey instrument probably undercounts wage cuts.

In a comment on Card and Hyslop (1997), Shea (1997) assesses the reliability of wage reports of union workers in the PSID. Shea matches union workers in the PSID to union wage settlements by industry, occupation, location, and year. Since very few of the reported wage cuts align with union wage concessions, Shea concludes that most nominal wage cuts in the PSID are attributable to measurement error. A problem with Shea's method is that wages of union workers change without corresponding changes in union pay scales. Union wages are typically assigned to jobs, and workers regularly move from job to job in some union firms. This was the case in the large manufacturing firm used in the PSID's Validation Study; indeed, workers in the validation study had great difficulty reporting hourly wages because they changed job assignments week-to-week and even day-to-day (Bound, Brown, Duncan, and Rodgers 1994). ${ }^{3}$

Altonji and Devereux (1997) provide maximum-likelihood estimates of an empirical model of wage rigidity and measurement error. They exploit cross-sectional variation in the position of the wage change distribution to estimate thinning. That is, Altonji and Devereux replace Kahn's (1997) time-series variation with cross-sectional variation in the distribution's position, and they add a distributional assumption in the process. In addition, Altonji and Devereux simultaneously estimate the variance of the measurement component. For their model to account for the spike at zero nominal wage growth, small wage cuts must be censored. Hence, the presence of small wage cuts in the data must (in their model) be attributed to measurement error. Altonji and Devereux conclude that about 80 percent of observed wage cuts are an artifact of measurement error; however, this would overstate the extent of measurement error if some small wage cuts were genuine.

The extent of measurement error is important for assessing the frequency of nominal wage cuts but not for the complementary question posed in this paper: Is there evidence of downward rigidity reducing the frequency of nominal wage cuts? Adding a symmetric measurement-error component would not bias any of the skewness tests or thinning measures. 


\section{WAGE CHANGES IN THE PSID}

To determine whether wage changes are skewed away from wage cuts, I use data from the PSID, which has followed thousands of households since 1968. The PSID includes annual observations covering survey week pay with the main employer. My measure of wages is the respondent's report of his survey week pay on his main job. For hourly workers, I use the straighttime hourly wage rate. For salaried workers; I do not convert salaries into hourly wage rates; hours-induced wage variability might mask salary rigidity. This is particularly important in light of the errors in reported hours of work (Bound, Brown, Duncan, and Rodgers 1994). Wage changes are the annual differences of log wages times 100.

My data set combines the PSID's 1992 cross-year individual file with 22 annual family files. Because downward wage rigidities are not expected to be important for workers who change employers, the sample is limited to household heads (since 1971) and spouses (since 1979) who stayed with their employers since the previous year (i.e., stayers). To be included in the sample, a worker must al so report his wage in adjacent years. ${ }^{4}$ In the resulting sample, 5,887 persons contribute 34,633 person-year observations on wage changes - an average of nearly six wage-change observations per person.

\section{Do Wage Changes Reflect Money Illusion?}

The bigger issue is money illusion. Downward wage rigidities associated with infrequent wage cuts would constitute money illusion, but placing the issue in a wider context is essential. The broader question is: How do nominal wages move with the price level? Or equivalently: How does the rate-of-change of nominal wages vary with the inflation rate? Perhaps some nominal wage cuts are censored at zero, but the overall distribution of wage changes could be tightly linked to inflation.

This is the case in longitudinal data from the PSID. For each annual sample

\begin{tabular}{|c|c|c|c|c|}
\hline \multicolumn{5}{|c|}{$\begin{array}{l}\text { Nominal Wage Changes and Inflation } \\
\text { Panel Study of Income Dynamics, 1971-92 }\end{array}$} \\
\hline \multirow[b]{2}{*}{ Variable } & \multicolumn{4}{|c|}{ Inflation Process } \\
\hline & & $\operatorname{RIMA}(0,1,1)$ & $\operatorname{AR}(3)$ & $\operatorname{ARIMA}(0,1,1)$ \\
\hline Intercept & $\begin{array}{l}3.309 \\
(.602)\end{array}$ & $\begin{array}{l}3.063 \\
(.589)\end{array}$ & $\begin{array}{l}2.847 \\
(.645)\end{array}$ & \\
\hline Inflation & $\begin{array}{c}.840 \\
(.103)\end{array}$ & & & \\
\hline Anticipated Inflation & & $\begin{array}{l}.880 \\
(.101)\end{array}$ & $\begin{array}{l}.928 \\
(.113)\end{array}$ & $\begin{array}{l}.918 \\
(.049)\end{array}$ \\
\hline Unanticipated Inflation & & $\begin{array}{l}.584 \\
(.176)\end{array}$ & $\begin{array}{l}.592 \\
(.183)\end{array}$ & $\begin{array}{l}.717 \\
(.100)\end{array}$ \\
\hline$R^{2}$ & .777 & .810 & .805 & .018 \\
\hline No. of Observations & 21 & 21 & 21 & 34,633 \\
\hline Unit of Observations & Annual Avg. & Annual Avg. & Annual Avg. & Individual $^{b}$ \\
\hline \multicolumn{5}{|c|}{$\begin{array}{l}\text { Least-squares regressions with standard errors in parentheses. Nominal wage changes are for } \\
\text { stayers in the PSID; inflation is based on the GDP Deflator. All variables are computed as annual } \\
\text { differences of logs. }\end{array}$} \\
\hline \multicolumn{5}{|c|}{$\begin{array}{l}\text { Additional regressors include years of age and education, as well as indicators of sex, race, mar- } \\
\text { riage, disability, occupation, industry, and union status, and change in union status; an intercept } \\
\text { is also included. }\end{array}$} \\
\hline
\end{tabular}

of stayers, I compute the average rate-ofchange of nominal wage over the previous year. Table 1 contains the results of regressing this annual wage change variable (in percentage terms) on the rate of inflation, based on the GDP Deflator. Consistent with my earlier findings ( $M$ CLaughlin 1994, p. 403), nominal wages move closely with the price level. The estimated effect is .84 , which is 1.6 standard deviations from one, so the hypothesis that nominal wages and prices move one for one is not rejected. The test is not decisive, so a suspicion of incomplete indexing of wages to prices might remain.

However, suspicion of incomplete indexing or money illusion vanishes if the inflation rate is partitioned into anticipated and unanticipated components. To reach this conclusion, I use time-series methods to generate one-step-ahead forecasts of inflation (i.e., anticipated inflation) and forecast errors (i.e., unanticipated inflation). Like Pearce (1979), and Fama and Gibbons (1984), I find that the inflation rate is the sum of a random-walk component and a stationary component; in par-

\footnotetext{
${ }^{4}$ Also excluded are top-coded observations, which were common during the mid-1970s. See McLaughlin (1999) for details of the sample exclusions.
} 
ticular, the first difference of the inflation rate follows a first-order moving-average process (i.e., $M A(1)$ ), so the inflation rate is an integrated first-order moving-average (i.e., ARIMA $(0,1,1)$ ) process. (Details are available on request.)

Table 1 displays the results of regressing nominal wage changes on anticipated and unanticipated inflation rates. Nominal wage changes move one-for-one with anticipated inflation, and there is a strong (but weaker) positive relationship between nominal wage changes and unanticipated inflation. The results are robust to al ternative specifications of the time-series process. For instance, in Table 1, the relationship between nominal wage changes and inflation components is essentially unchanged if a third-order autoregressive model is used to compute anticipated and unanticipated inflation rates. So incomplete indexing of nominal wages to prices appears to reflect that inflation is not fully anticipated.

This result is confirmed on individuallevel data from the PSID. ${ }^{5}$ Here I regress an individuals' nominal wage change on anticipated and unanticipated inflation rates, as well as on the labor economist's standard set of regressors (including years of age and education and indicators of sex, race, occupation, industry, and union status). The estimated effects of the inflation components, which are reported in Table 1, confirm the pattern. From the relationship between nominal wage changes and components of inflation, there is no evidence of money illusion.

In terms of monetary policy, this suggests no role for moderate inflation in greasing the wheels of the labor market. Suppose, however, that one detects evidence of nominal rigidity by focusing on the nominal wage change distribution around zero. Such evidence of money illusion might be treated as a problem to be solved by monetary policy, but downward rigidity around zero should be treated as a higher-order problem. The wider context- that the overall distribution of nominal wage changes moves one-for-one with anticipated inflation-must not be dropped.

\section{Subtracting the Left Side from the Right Side}

Visual inspection of a distribution can sometimes reliably detect departures from symmetry. But visually inspecting the histogram, matching bars on each side of the distribution, can be misleading if departures from symmetry are not severe. This is particularly important in the current context, where stayers' wage change histograms in the PSID appear to be fairly symmetric (M cLaughlin 1994).

To aid the eye, I present symmetrically differenced histograms. I compute the histogram based on equal-sized intervals around the median, flip the left side of the distribution over onto the right, and difference the two. ${ }^{6}$ Here I subtract the left from the right, so a positive (negative) value indicates that the right (left) side of the distributions is thicker than the left (right) side over that particular interval. Since the histogram sums to 100 percent (with 50 percent on each side of the median), the symmetrically differenced histogram sums to zero.

For a sample drawn from a symmetric distribution, the symmetrically differenced histogram would be a scatter of points al ong the zero line. Alternatively, suppose the left side of the nominal wage change distribution was thinned below zero, with these would-be wage cuts piling up at zero. Such a density function is illustrated in the upper-left panel of Figure 1, and its symmetrically differenced histogram in the lower-left panel. Since the spike at zero lies bel ow the median, the symmetrically differenced histogram has a negative spike at twice the median. (A reference line is drawn at the median.) Values are zero up to twice the median, and positive values beyond this point reflect that the left tail is thinner than the right.

In addition, perhaps some small wage increases or decreases are censored at zero. The right two panels of Figure 1 illustrate such a density function and its symmetrically differenced histogram. By censoring half of the small wage changes, two positive spikes surround the negative spike in the lower-right panel. So if nominal rigidities 


\section{Figure 1}

\section{Censoring Wage Cuts and Small Wage Changes}
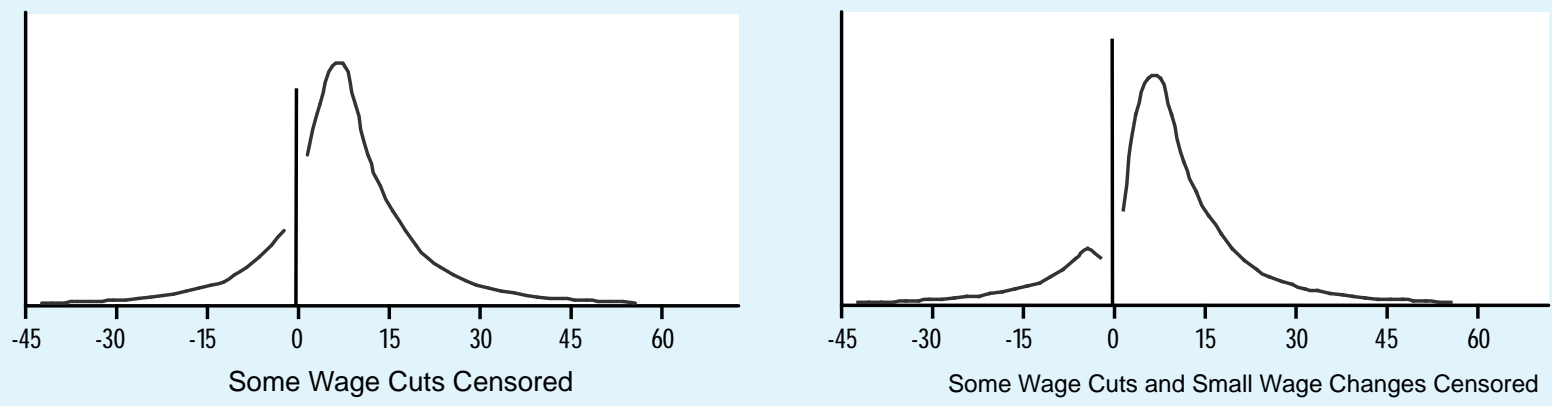

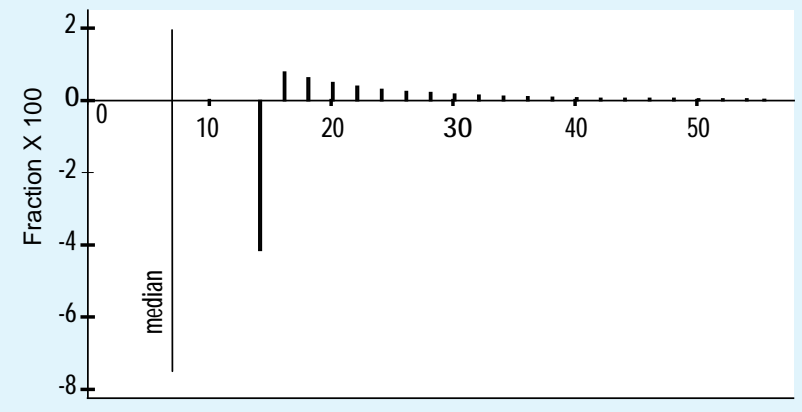

Symmetrically Differenced Histogram

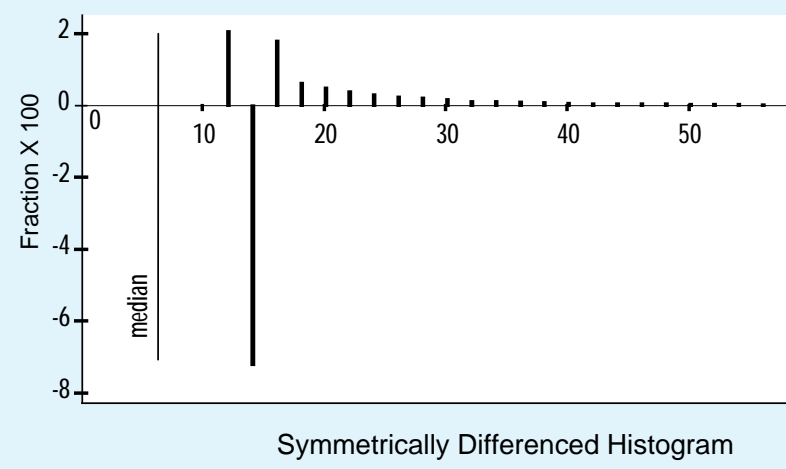

censor some wage cuts and some small wage changes, the symmetrically differenced histogram should resemble the lower-right panel of Figure 1.

For the sample of stayers in the PSID, the symmetrically differenced histogram in Figure 2 does resemble the lower-right panel in Figure 1. (The stayers' histogram of wage changes is also depicted in Figure 2.) Small positive spikes surround a large negative spike at twice the median, which indicates some censoring of small wage changes. Values tend to be positive for wage changes beyond twice the median, which indicates that, below zero, the left side of the distribution is thinner than the right. But this symmetrically differenced histogram reveals more than partial censoring of small wage changes and wage cuts. Two negative values appear just to the right of the median reference line. Thus, wage changes just to the left of the median are more common than those just to the right of the median. This prop- erty is common for right-skewed distributions, such as the log-normal. But the presence of this property in the context of wage changes is important. There is more to the skewness of the wage change distribution than is implied by the censoring of some wage cuts and some small wage changes.

\section{Test Statistics}

Visual evidence from the symmetrically differenced histograms can be put to formal tests by computing the skewness coefficient, the mean-median difference, and the sign test statistic. On a sample of size $\mathrm{N}$ from distribution function $\mathrm{F}, \mathrm{I}$ test the null hypothesis $\mathrm{H}_{0}$ that the distribution of wage changes $x$ is symmetric; that is, $F(x)=1-F(-x)$ for all values of the random variable $x$.

The skewness coefficient, perhaps the most familiar measure of symmetry, is the ratio of the third central moment of $x$ to 


\section{Figure 2}

Distribution of Nominal Wage Changes for Stayers
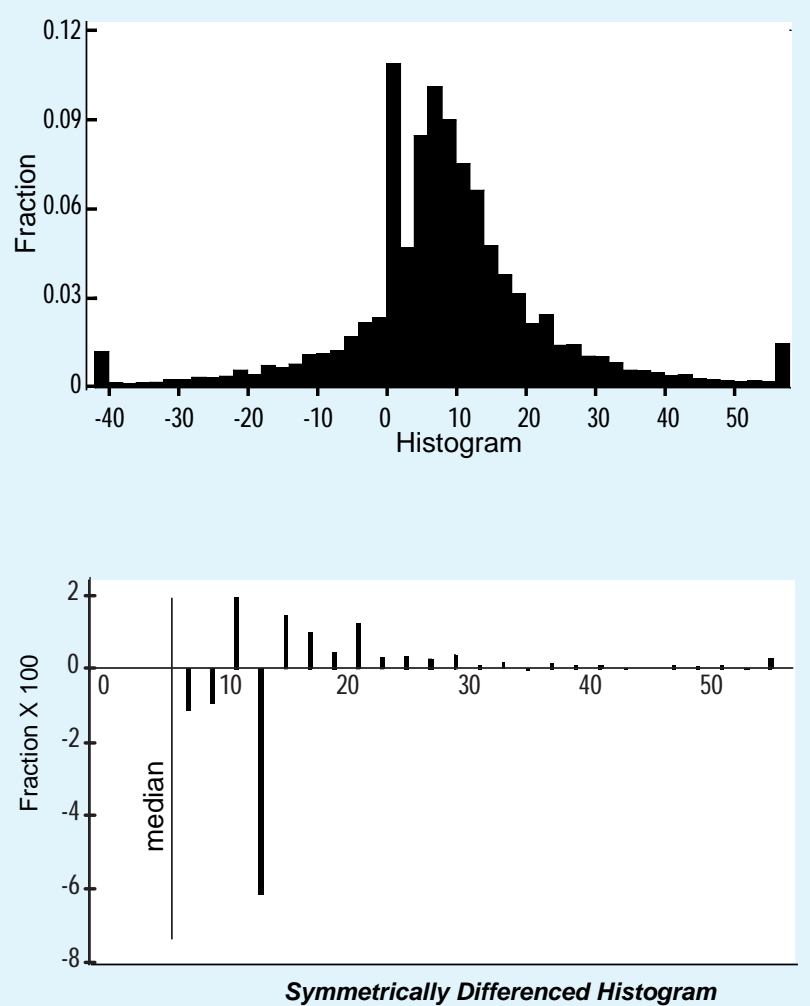

the cubed standard deviation of $\mathrm{x}$. Under the null hypothesis $\mathrm{H}_{0}$, the asymptotic distribution of the skewness coefficient is normal with mean zero and variance:

$$
\frac{9}{N}+\frac{\mu_{6}-6 \mu_{4} s^{2}}{N s^{2}}
$$

where $s$ is the standard deviation of $x$, and $\mu_{\mathrm{k}}$ denotes the kth central moment of $\mathrm{x}$ (Gupta 1967). If $F$ were the normal distribution, then the variance of the skewness coefficient would simplify to $6 / \mathrm{N}$.

As a test of symmetry, the skewness coefficient has problems with false negatives. First, some skewed distributions have zero third moments (M ood, Graybill, and Boes 1974, p. 76). Second, because the skewness coefficient is sensitive to tail observations, the fourth and sixth moments associated with fat-tail distribu- tions severely inflate the variance of the test statistic; that is, fat tails produce high-variance skewness coefficients. This explains why skewness coefficients applied to wage change distributions, which have fat tails (McLaughlin 1994), tend to jump around from sample to sample (Crawford and Harrison 1997) and are sensitive to tail observations (Lebow, Stockton, and Wascher 1995). Properly computed standard errors reflect this, but long-tails render the test weak in detecting even strongly skewed alternative distributions. Indeed, the skewness coefficient has trouble detecting the asymmetry of the log-normal distribution (McLaughlin 1999).

Table 2 provides a good illustration of this problem with the skewness coefficient. Despite the apparent skewness of the wage change distribution in the PSID, a test based on the skewness coefficient fails to reject the null hypothesis of symmetry. The estimated skewness coefficient is .36, but its standard error is .30; however, since the distribution of wage changes has fat tails, this test's failure to detect skewness is not surprising.

M ost tables of critical values for the skewness coefficient are based on a normal distribution of $x$. If the distribution of $x$ has fat tails, such critical values are biased toward zero, which generates a problem with false positives. For comparison, Table 2 also includes the standard error of the skewness coefficient under normality. This standard error is as small as .01. Symmetry is clearly rejected, but at this point, whether the rejection is valid or spurious remains unknown.

A simple by-product of positive (negative) skewness is that the mean lies to the right (left) of the median, which motivates the mean-median difference (Hotelling and Solomons 1932) as a test. Under the null hypothesis of symmetry, the difference between the mean and the median is expected to be zero; furthermore, if the median $\mathrm{m}$ is treated as known, then by the Central Limit Theorem, the meanmedian difference is asymptotically normal with variance $\mathrm{s}^{2} / \mathrm{N}$. The mean- 
median difference reported in Table 2 is . 81 percentage points, which clearly rejects symmetry in favor of a wage change distribution skewed away from wage cuts. Indeed, the mean is estimated to be 8.4 standard errors to the right of the median.

What lies between the mean and the median also contributes to a test of symmetry. The sign test statistic (e.g., Gastwirth 1971) counts (and signs) the observations between the mean and median. Under $\mathrm{H}_{0}$, the number of observations bel ow the mean is distributed binomial with parameters $\mathrm{N}$ and $1 / 2$. By invoking the normal approximation to the binomial, the number of observations between the mean and the median is approximately normal with mean zero and variance $\mathrm{N} / 4$. In Table 2 , results of the sign test applied to wage changes in the PSID also reject the null hypothesis of symmetry. In a sample of this size, it would not be surprising to find 100 or so observations between the mean and the median. More than 1,200 observations lie between the mean and median, however.

Table 2 also contains a check of the sensitivity of the symmetry tests to the presence of the spike at zero. If all the zero-wage-change observations were would-be wage cuts or small wage changes censored at zero, these observations would belong in the calculations. Alternatively, these observations could reflect the rounding of wage responses or the timing of the survey (with some wages changing soon after the survey date). N either factor constitutes an asymmetry of wage changes. By removing the spike at nominal zero, the skewness tests can isolate the contribution of "thinning" the distribution below zero. In the lower half of Table 2, I report the skewness test statistics on the sample that excludes observations with no change in nominal wages. All three skewness test statistics fall, providing weaker rejections of symmetry. But wage changes remain skewed right.

\section{Thinning of the Distribution Below Zero}

W hile these tests reveal skewness, they do not address the question of skew-

\begin{tabular}{|c|c|c|c|c|}
\hline \multicolumn{5}{|c|}{$\begin{array}{l}\text { Skew ness Test Statistic sa } \\
\text { Panel Study of Income Dynamics, 1971-92 }\end{array}$} \\
\hline Sample & $\begin{array}{l}\text { Skew ness } \\
\text { Coefficient }\end{array}$ & $\begin{array}{l}\text { Mean - } \\
\text { Median }\end{array}$ & $\begin{array}{l}\text { Sign } \\
\text { Test }\end{array}$ & $\begin{array}{l}\text { Thinness } \\
\text { Measure }\end{array}$ \\
\hline $\begin{array}{l}\text { Including the Spike } \\
\text { at Zero }\end{array}$ & $\begin{array}{c}0.335 \\
(0.298) \\
{[0.013]}\end{array}$ & $\begin{array}{c}0.811 \\
(0.096)\end{array}$ & $\begin{array}{l}1,242.5 \\
(93.1)\end{array}$ & 7.89 \\
\hline $\begin{array}{l} \pm 48 \text { Point Band Around } \\
\text { the Median }\end{array}$ & $\begin{array}{c}0.077 \\
(0.024) \\
{[0.013]}\end{array}$ & $\begin{array}{c}0.687 \\
(0.070)\end{array}$ & $\begin{array}{c}1,068.5 \\
(91.8)\end{array}$ & 7.85 \\
\hline $\begin{array}{l} \pm 5 \text { Point Band Around } \\
\text { the Median }\end{array}$ & $\begin{array}{c}0.058 \\
(0.012) \\
{[0.020]}\end{array}$ & $\begin{array}{c}0.065 \\
(0.022)\end{array}$ & $\begin{array}{l}200.5 \\
(59.8)\end{array}$ & \\
\hline $\begin{array}{l}\text { Excluding the Spike } \\
\text { at Zero }\end{array}$ & $\begin{array}{c}0.248 \\
(0.291) \\
{[0.014]}\end{array}$ & $\begin{array}{l}0.586 \\
(0.104)\end{array}$ & $\begin{array}{l}837.5 \\
(89.2)\end{array}$ & 4.11 \\
\hline $\begin{array}{l} \pm 48 \text { Point Band Around } \\
\text { the Median }\end{array}$ & $\begin{array}{r}-0.023 \\
(0.024) \\
{[0.014]}\end{array}$ & $\begin{array}{c}0.470 \\
(0.075)\end{array}$ & $\begin{array}{l}725.5 \\
(87.9)\end{array}$ & 4.04 \\
\hline $\begin{array}{l} \pm 5 \text { Point Band Around } \\
\text { the Median }\end{array}$ & $\begin{array}{c}0.151 \\
(0.012) \\
{[0.020]}\end{array}$ & $\begin{array}{c}0.206 \\
(0.023)\end{array}$ & $\begin{array}{l}302.0 \\
(60.1)\end{array}$ & \\
\hline
\end{tabular}

ness away from wage cuts. To address this question, Table 2 includes Lebow, Stockton, and Wascher's (1995) measure of thinning, the proportion above twice the median minus the proportion below zero. The wage change distribution below zero is nearly 8 percentage points thinner than its mirror image on the right side of the distribution. If zero wage change observations are excluded, the thinness measure falls to about 4 percentage points. Intertemporal variation in the wage change distribution provides another way to identify thinning of the distribution below zero (Kahn 1997). This idea is simple and powerful. Take an interval a few percentage points bel ow the median. When nominal wage growth is high (i.e., when inflation tends to be high), that interval lies above zero. In low nominal wage growth years, that interval might lie below zero. (In some years, the interval might span zero.) Kahn's idea is to compare the histogram's values for that interval when it lies to the right and left of zero. 
If the value of the histogram on the interval is smaller when it lies below zero, there is evidence of wage changes being skewed away from wage cuts.

Kahn estimates econometric specifications that essentially weight all the intervals that move above and below zero. But her idea can be implemented most directly by picking a few intervals that pass zero. My symmetrically differenced histograms use intervals two percentage points wide. The third and fourth intervals below the median (i.e., 4-6 and 6-8 percentage points below the median) lie above zero in high inflation years and below zero in low inflation years. For each interval, Table 3 reports values of the histogram in years when the interval was above and below zero. Wage change observations on interval 3 are 2.1 percent more common when that interval lies above zero. For interval 4, the difference of the histogram values is only .4 percent.

As with any difference estimator, there is the question of a control group. If the sample in low wage-growth years has lower variance of wage changes, the tails of the distribution would be thinner even if would-be wage cuts were not censored at zero. Perhaps the composition of the sample differs when nominal wage changes are higher, or as Card and Hyslop (1997, p. 86) argue, perhaps the dispersion of wage changes is affected by inflation. ${ }^{7}$ This issue can be addressed with a difference-in-difference estimator. I use the change in the corresponding interval above the median as the control. Difference-in-difference estimates in Table 3 are a bit larger: 2.5 on interval 3 and 1.9 on interval 4. Overall, these histogram difference estimates do point to a thinning of tails below nominal zero, with a thinning of one-third to one-half of would-be cuts near zero.

\section{Are Censored Wage Cuts the O nly Source of Skewness?}

If thinning of the wage-change distribution below zero were the only source of skewness, then (a) extreme tail observations would not be the main source of skewness, and (b) wage changes close to the median would be symmetric, since these observations would not be affected by any downward nominal rigidity at zero. That is, the distribution's right side is predicted to be heavier than its left side over the range of wage cuts, but not over the entire range of wage changes. These implications can be checked directly.

First, to check whether skewness is limited to tail observations, I exclude wagechange observations that contribute to the bottom and top histogram bars in Figure 2 . This eliminates 1.19 percent from the left side and 1.44 percent from the right, so these tail observations contribute to the right skew. Skewness test statistics are computed on the remaining wage-change observations, which lie within 48 percentage points of the median. The results in Table 2 reveal that positive skewness survives trimming the tails. Extreme wage change observations do not account for all of the skewness, a result consistent with downward nominal rigidities.

Second, based on the symmetrically differenced histogram in the lower panel of Figure 2, wage changes just to the left of the median are more common than those just to the right of the median. This property is typical of right-skewed distributions such as the log-normal. In Table 2, on the sample of wage changes within 5 percentage points of the median, the test statistics reject symmetry. ${ }^{8}$ Since this band does not include wage cuts, the spike at zero, or small wage increases, the source of skewness of wage changes is not limited to the censoring of would-be wage cuts and small wage changes. Skewness seems to be a more general property of wage changes.

Skewness close to the median presents a problem for the thinning estimates of Lebow, Stockton, and Wascher (1995) and Card and Hyslop (1997); these estimates rely on the mirror-image assumption that the distribution of wage changes would be symmetric if not for downward nominal rigidity. If the overall distribution were skewed right, which is consistent with the evidence close to the median, then the mirror-image assumption would be violated, and their estimates of thinning would overstate the extent of downward nominal rigidity. 
How severe is the bias? This depends on how skewed the overall distribution would have to be to generate the observed skewness near the median. One could generalize from the estimates of skewness near the median to generate an overall distribution that is skewed for reasons unrelated to downward nominal rigidities. In particular, the BoxCox transformation that renders the observations close to the median symmetric could be applied to the overall distribution to generate a counterfactual distribution. ${ }^{9}$ A corrected estimate of thinning differences the proportions of wage cuts in the actual and counterfactual distributions. ${ }^{10}$

Although skewness near the median might not appear strong in Table 2, observations near the median are strongly skewed, more skewed than can be explained by even a log-normal distribution. In particular, sending the Box-Cox parameter to zero is not sufficient to produce symmetry near the median. The implied counterfactual distribution would be so strongly skewed that "corrected" estimates of thinning would identify upward nominal rigidity. Although these unreported results do not qualify as serious corrections, they are instructive. Skewness near the median is too severe to ignore; and estimates of thinning by Lebow, Stockton, and Wascher and Card and Hyslop probably overstate the extent of downward nominal rigidity substantially.

\section{Does Inflation Reduce Skew ness Away From Wage Cuts?}

The evidence that wage changes are skewed is definitive, but inflation's role remains to be determined. Does inflation render less restrictive a constraint against nominal wage cuts? Or, if the nominal rigidity at zero is the source of skewness away from wage cuts, does inflation reduce the skewness of the wage change distribution? By identifying how the test statistics vary with inflation, this can be checked directly.

If inflation relaxes the constraint, then skewness of the distribution of wage changes would be less severe in high-infla-

\begin{tabular}{|c|c|c|}
\hline \multicolumn{3}{|c|}{$\begin{array}{l}\text { Histogram Difference Estimates of Downward } \\
\text { Nominal Rigiditiesa } \\
\text { Panel Study of Income Dynamics, 1971-92 }\end{array}$} \\
\hline Sample & Interval 3 & Interval 4 \\
\hline $\begin{array}{l}\text { Left of Median } \\
\text { Years When Interval Is Above Zero } \\
\text { Years When Interval Is Below Zero } \\
\text { Difference }\end{array}$ & $\begin{array}{l}6.29 \\
4.23 \\
2.06\end{array}$ & $\begin{array}{l}3.36 \\
2.96 \\
0.40\end{array}$ \\
\hline $\begin{array}{l}\text { Right of Median } \\
\text { Years When Interval }\left.\right|^{b} \text { Is Above Zero } \\
\text { Years When Interval }\left.\right|^{\mathrm{b}} \text { Is Below Zero } \\
\text { Difference }\end{array}$ & $\begin{array}{r}4.43 \\
5.82 \\
-0.39\end{array}$ & $\begin{array}{r}4.57 \\
6.04 \\
-1.47\end{array}$ \\
\hline Difference-in-Difference & 2.45 & 1.87 \\
\hline \multicolumn{3}{|c|}{$\begin{array}{l}\text { Table entries are histogram values and differences in histogram values. The length of each inter- } \\
\text { val is two percentage points. Intervals } 3 \text { and } 4 \text { lie 4-6 and } 6-8 \text { percentage points away from } \\
\text { year-specific medians. }\end{array}$} \\
\hline
\end{tabular}

tion periods. To test this, I compute each test statistic (i.e., skewness coefficient, mean-median difference, sign test, and thinness measure) annually. (The four test statistics are highly correlated across years.) The results of correlating the annual test statistics with inflation are reported in Table 4. The correlations are small and statistically insignificant, and only the thinness measure's correlation is negative. So wage changes in the PSID contain no evidence of less skewed distributions of wage changes in years when inflation was higher.

This result is robust to partitioning inflation into anticipated and unanticipated components. For inflation to grease the wheels, it must shift the distribution of wage changes away from zero, and this is more likely for anticipated inflation. Table 4 contains correlations of the skewness statistics separately with anticipated and unanticipated inflation. Based on the three main skewness measures, neither anticipated nor unanticipated inflation reduces the skewness of nominal wage changes. Only the thinness measure correlates significantly negatively with anticipated inflation.

The negative correlations of inflation and anticipated inflation with the thinness

\footnotetext{
${ }^{9}$ The Box-Cox transformation is $(y-1)^{\lambda} / \lambda$, where $y$ is $1+\Delta w$. For $0 \leq \lambda<1$, this transformation is strictly concave, which reduces skewness to the right.

${ }^{10}$ This is a difference-in-difference estimator. Wage-change observations close to the median constitute the control group, which are unaffected by the treatment of downward nominal rigidity. These observations are used to estimate how much thicker the right side would be than the left in the absence of downward nominal rigidity. This adjustment factor is then differenced from Lebow, Stockton, and Wascher's or Card and Hyslop's difference estimates.
} 


\section{Table 4}

\section{Correlations of Skewness Statistics With Inflation}

Panel Study of Income Dynamics, 1971-92

\begin{tabular}{lccc} 
Sample and Test Statistic & Inflation & $\begin{array}{c}\text { Anticipated } \\
\text { Inflation }\end{array}$ & $\begin{array}{c}\text { Unanticipated } \\
\text { Inflation }\end{array}$ \\
\cline { 2 - 4 } All Workers & 0.30 & 0.23 & 0.10 \\
$\quad$ Skewness Coefficient & 0.07 & -0.14 & 0.36 \\
Mean-Median Difference & 0.08 & -0.08 & 0.27 \\
Sign Test Statistic & -0.33 & -0.50 & 0.31 \\
$\quad$ Thinness Measure & & & \\
Union Workers & 0.03 & -0.14 & 0.34 \\
Skewness Coefficient & -0.55 & -0.69 & 0.36 \\
Mean-Median Difference & -0.53 & -0.66 & 0.34 \\
Sign Test Statistic & -0.60 & -0.68 & 0.27 \\
Thinness Measure & & & \\
Nonunion Workers & 0.29 & 0.24 & 0.06 \\
Skewness Coefficient & 0.21 & 0.11 & 0.18 \\
Mean-Median Difference & 0.16 & 0.07 & 0.16 \\
Sign Test Statistic & -0.10 & -0.12 & 0.05 \\
Thinness Measure & & & \\
Hourly Workers & 0.02 & 0.05 & 0.06 \\
Skewness Coefficient & -0.04 & -0.37 & 0.72 \\
Mean-Median Difference & -0.10 & -0.38 & 0.60 \\
Sign Test Statistic & -0.65 & -0.79 & 0.31 \\
Thinness Measure & & & \\
Salaried Workers & & 0.37 & 0.13 \\
Skewness Coefficient & 0.44 & 0.08 & 0.12 \\
Mean-Median Difference & 0.14 & 0.17 & 0.14 \\
Sign Test Statistic & 0.24 & 0.06 & 0.42 \\
Thinness Measure & 0.27 & & \\
& & &
\end{tabular}

a Correlations are computed on 21 annual observations. The sign test statistic is normalized by its standard deviation.
${ }^{11}$ Since Card and Hyslop (1997) use the same thinness measure, their evidence of less thinning in high inflation periods suffers from the same bias. measure are probably biased down. The median wage change varies with inflation, hence thinning is measured farther out in the distribution's tails in high inflation years. Maintain the mirror-image assumption, and the correlation of thinness with inflation detects inflation's role in relaxing any constraint of nominal wage cuts. Drop the mirror-image assumption, and the correlation is al most surely biased down. Suppose the distribution of wage changes is skewed right for reasons unrelated to downward rigidity. Then moving farther out in the tails surely reduces the measure of thinness even in the absence of downward nominal rigidity. Consequently, the correlation of Lebow, Stockton, and Wascher's thinness measure with inflation is biased down. ${ }^{11}$ Correlations of the other symmetry test statistics with inflation are not sensitive to skewness unrelated to downward nominal rigidity.

The evidence of strong skewness near the median leaves little role for downward nominal wage rigidity, and this is confirmed by little evidence of negative correlations between the skewness test statistics and inflation. Alternatively, if I had found strong negative correlations with inflation, then the detected skewness near the median would not be sufficiently strong to account for overall skewness and thinning. The complementarity of these tests- near the median and correlations with inflationis particularly useful in explaining differences across groups. With only downward nominal rigidity, groups with strong skewness should have strong negative correlations with inflation. This link would be broken if there were evidence- in the form of skewness near the median - of an intervening factor, another source of skewness.

\section{Do Unions and Method of Pay Matter?}

My results cover the sample of stayers. Yet the literature has drawn a sharp distinction between hourly and salaried workers (i.e., by method of pay), and perhaps a distinction should be drawn between union and nonunion workers. Do unions and method of pay matter?

Table 5 contains the skewness test statistics, including difference-in-difference estimates based on histogram shifts, by union status and method of pay. Wage changes of both union and nonunion workers are skewed right, although the wage changes of nonunion workers seem to be more highly skewed. This contradicts my evidence, based on the skewness coefficient, that wage changes of nonunion workers are symmetric (M cLaughlin 1994). The high variance of the skewness coefficient in the presence of a fat-tailed wagechange distribution resolves the paradox.

A sharper distinction emerges between hourly and salaried workers. The evidence of right-skewed wage changes for hourly workers is overwhelming; wage changes of salaried workers are also skewed, but the 


\section{Skewness Test Statistics by Union Status and Method of Paya Panel Study of Income Dynamics, 1971-92}

\begin{tabular}{|c|c|c|c|c|c|c|c|}
\hline \multirow[b]{2}{*}{ Sample ${ }^{b}$} & \multirow[b]{2}{*}{$\begin{array}{c}\text { Sample } \\
\text { Size }\end{array}$} & \multirow[b]{2}{*}{$\begin{array}{l}\text { Skew ness } \\
\text { Coefficient }\end{array}$} & \multirow[b]{2}{*}{$\begin{array}{l}\text { Mean - } \\
\text { Median }\end{array}$} & \multirow[b]{2}{*}{$\begin{array}{l}\text { Sign } \\
\text { Test }\end{array}$} & \multirow[b]{2}{*}{$\begin{array}{l}\text { Thinness } \\
\text { Measure }\end{array}$} & \multicolumn{2}{|c|}{ Difference-in-Difference } \\
\hline & & & & & & Interval 3 & Interval 4 \\
\hline Entire Histogram & & & & & & & \\
\hline Union Workers & 8,013 & $\begin{array}{c}0.087 \\
(0.232)\end{array}$ & $\begin{array}{c}0.615 \\
(0.151)\end{array}$ & $\begin{array}{l}286.5 \\
(44.7)\end{array}$ & 6.23 & 0.90 & 1.09 \\
\hline Nonunion Workers & 22,749 & $\begin{array}{l}0.226 \\
(0.362)\end{array}$ & $\begin{array}{c}0.773 \\
(0.126)\end{array}$ & $\begin{array}{l}721.5 \\
(75.4)\end{array}$ & 8.24 & 2.55 & 0.60 \\
\hline Hourly Workers & 14,271 & $\begin{array}{c}1.674 \\
(1.341)\end{array}$ & $\begin{array}{c}1.106 \\
(0.108)\end{array}$ & $\begin{array}{l}839.5 \\
(59.7)\end{array}$ & 10.85 & NA & 1.79 \\
\hline Salaried Workers & 14,758 & $\begin{array}{c}0.049 \\
(0.288)\end{array}$ & $\begin{array}{c}0.326 \\
(0.175)\end{array}$ & $\begin{array}{l}161.0 \\
(60.7)\end{array}$ & 4.74 & 1.21 & 0.03 \\
\hline 5 Point Band Around the Median & & & & & & & \\
\hline Union Workers & 3,845 & $\begin{array}{c}0.028 \\
(0.023)\end{array}$ & $\begin{array}{c}0.011 \\
(0.043)\end{array}$ & $\begin{array}{c}16.5 \\
(31.0)\end{array}$ & & & \\
\hline Nonunion Workers & 8,796 & $\begin{array}{l}0.062 \\
(0.015)\end{array}$ & $\begin{array}{c}0.057 \\
(0.028)\end{array}$ & $\begin{array}{l}140.0 \\
(46.9)\end{array}$ & & & \\
\hline Hourly Workers & 7,056 & $\begin{array}{c}0.047 \\
(0.017)\end{array}$ & $\begin{array}{c}0.055 \\
(0.031)\end{array}$ & $\begin{array}{l}120.0 \\
(42.0)\end{array}$ & & & \\
\hline Salaried Workers & 4,996 & $\begin{array}{c}0.022 \\
(0.020)\end{array}$ & $\begin{array}{c}0.083 \\
(0.038)\end{array}$ & $\begin{array}{r}65.0 \\
(35.3)\end{array}$ & & & \\
\hline
\end{tabular}

departure from symmetry is much weaker. For instance, thinning is less than half as severe for salaried workers.

Table 5 also contains "near the median" skewness tests by union status and method of pay. Again, skewness near the median does not reflect downward nominal rigidity. $\mathrm{N}$ ear the median, wage changes of union workers are symmetric, while those of nonunion workers are clearly skewed. This contrasts with the results by method of pay. Both hourly and salaried workers' wage changes are weakly skewed right near the median. So, except in the case of union workers, there is evidence that the estimates of Lebow, Stockton, and Wascher as well as Card and Hyslop overstate the role of nominal rigidity in thinning the wage change distribution bel ow zero.

If the source of skewness were downward rigidity, then the skewness coefficients would be negatively correlated with inflation, and this is confirmed in Table 4 for union and hourly workers. On the union and hourly samples, correlations of three of the four test statistics with anticipated inflation (in the second column) are negative and fairly strong. There is no evidence of inflation relaxing downward nominal rigidity for nonunion and salaried workers.

Integrating these results, I find that the skewness of union workers' wage changes is all attributable to nominal rigidity. There is no evidence of skewness near the median, and the skewness statistics are negatively correlated with anticipated inflation. The source of the strongly skewed wage changes of nonunion workers, however, is not nominal rigidity. The skewness statistics are not correlated with anticipated inflation, and strong skewness of nonunion workers' wage changes near the median confirms the result. The wage changes of hourly workers are strongly skewed right, and some of this is unrelated to nominal rigidity (based on skewness near the median); since anticipated inflation reduces the skewness of hourly workers' wage changes, some of the skewness is a consequence of nominal rigidity. There is 
no evidence of downward nominal rigidity for salaried workers. Indeed, salaried workers' wage changes exhibit only mild skewness; that mild skewness is present near the median, and none of the skewness statistics is negatively correlated with inflation.

The union/nonunion comparison highlights the complementarity between the "near the median" and "inflation correlation" tests. Although the wage changes of nonunion workers are more skewed than those of union workers, correlations with inflation offer no evidence of downward nominal rigidity for nonunion workers. This would be anomalous if not for the evidence of strong skewness of nonunion workers' wage changes near the median. And this constitutes evidence of an intervening factor, another source of skewness.

\section{IF NOT NOMINAL RIGIDITY, THEN WHAT?}

A theme emerges: There is more to skewness of the wage-change distribution than downward nominal rigidity. If the source of skewness is not nominal rigidity, then what is it? Consider three possibilities. First, perhaps there is an aversion to wage cuts in real terms, and this thins the left side of the distribution of real wage changes. Since inflationary expectations vary across employment matches, a focal point at zero real-wage change is not implied. Downward real-wage rigidity simply implies that wage changes would be skewed to the right.

Second, self-selection skews wage changes to the right (Weiss and Landau 1984). The economic intuition is simple. We observe the distribution of accepted wage offers. Some wage offers are not accepted, and these are more likely to come from the left side of the wage-change distribution. Offer a worker a 20 percent wage increase, and he would be likely to accept it; offer that worker a 20 percent cut in pay and he would be likely to quit. Indeed, rather than offer a worker a 20 percent cut, the employer would probably just lay him off. Hence, wage changes from the left side of the distribution are more likely to be truncated by turnover. By analyzing the sample of stayers, we introduce a bias toward right skew in the distribution of wage changes. And the size of the bias is unknown.

Third, pooling of samples with different distributions can generate spurious skewness. For instance, pooling samples of workers from different industries, as I have done herein, mixes the industry wage-change distributions. Mixing does not preserve symmetry ( M cLaughlin 1999), so pooling industry samples might skew the distribution of wage changes even if each industry's distribution were symmetric. Although this bias is potentially serious, I find that it is not the source of skewness in the overall distribution (McLaughlin 1999).

\section{WHAT DOES THIS MEAN FOR MONETARY POLICY?}

My purpose has been to identify common patterns and themes in the burgeoning literature on wage changes in panel data. Using data from the PSID, I confirm that wage changes are skewed to the right, there is a spike at no change in nominal pay, and below zero, the left side of the distribution is thinner than the right side. These patterns have been identified in the literature, but I cast new light on the subject.

I use several test statistics to detect asymmetry, and I show that, with the exception of the skewness coefficient, skewness tests are not sensitive to the choice of a test statistic. I identify the source of the problem others have found with the skewness coefficient: The fat tails of the wage change distribution tend to produce high-variance skewness coefficients. In response to Card and Hyslop's (1997) criticism of Kahn's (1997) histogram difference estimator of thinning, I estimate a difference-in-difference version of Kahn's estimator, which strengthens her results. Since as much as half of the spike at zero change in nominal wages might be attributable to rounding errors and the timing of survey interviews, I retest for skewness excluding these observations. 
The evidence of skewness is weaker, but the null hypothesis of symmetric wage changes is still rejected.

There is more to the skewness of wage changes than can be attributed to downward rigidity at zero. Here I break with the literature. First, I place the issue of downward rigidity in a wider context by documenting that nominal wage changes move one-for-one with anticipated inflation. Second, checking the mirror-image assumption of Lebow, Stockton, and Wascher (1995), and Card and Hyslop (1997), I find that wage changes near the median are skewed. This implies that the estimates of thinning of nominal wage cuts by Lebow, Stockton, and Wascher, as well as Card and Hyslop, overstate the extent of downward nominal rigidity. It also means that wage changes are skewed for reasons unrelated to nominal rigidity, perhaps as a result of self-selection associated with efficient turnover. Third, confirming my suspicion that skewness is not attributable to nominal rigidity, I find that the skewness of wage changes is unrelated to inflation, anticipated inflation, or unanticipated inflation. Fourth, although nonunion workers' wage changes are skewed to the right, the source of the skewness is not downward rigidity. Yet the weakly skewed wage changes of union workers do reflect downward rigidity, because union workers' wage changes near the median are not skewed, and the test statistics on the union sample are negatively correlated with anticipated inflation.

Few areas of economic research have more direct implications for economic policy than this one. The thorn in the side of the policy recommendation of stable prices (i.e., zero inflation) has been the labor market. Workers are subject to money illusion in the form of downward rigidity of nominal wages, or so the story goes. I do detect some nominal rigidity for union and hourly workers, but the magnitudes are smaller than others have found. And one must al ways remember the wider context: Nominal wages of workers who do not change employers do move one-for-one with anticipated inflation. Consequently, the labor market is not much of a thorn in the side of zero-inflation monetary policy.

\section{REFERENCES}

Akerlof, George, William Dickens, and George Perry. "The Macroeconomics of Low Inflation," Brookings Papers on Economic Activity (1996), pp. 1-59.

Altonji, Joseph, and Paul Devereux. "The Extent and Consequences of Downward Nominal Wage Rigidity." Manuscript, (October 1997).

Ahmad, Ibrahim, and Qi Li. "Testing Symmetry of an Unknown Density Function by the Kemel Method," Joumal of Nonparametric Statistics 7 (1997), pp. 279-93.

Bound, John, Charles Brown, Greg Duncan, and Willard Rodgers. "Evidence on the Validity of Cross-Sectional and Longitudinal Labor Market Data," Journal of Labor Economics 12, (July 1994), pp. 345-68.

, and Alan Krueger. "The Extent of Measurement Error in Longitudinal Earnings Data: Do Two Wrongs Make a Right?" Journal of Labor Economics 9, (January 1991), pp. 1-24.

Card, David, and Dean Hyslop. "Does Inflation 'Grease the Wheels of the Labor Market'?" In Reducing Inflation: Motivation and Strategy, Christina Romer and David Romer, eds., National Bureau of Economic Research Studies in Business Cycles, v. 30, University of Chicago Press, 1997, pp. 114-121.

Christofides, Louis, and Thanasis Stengos. "The Symmetry of the WageChange Distribution: Non-Parametric Tests Using Contract and Survey Data." Manuscript, (July 1998).

Craig, Ben. "Are Wages Inflexible?" Economic Commentary, Federal Reserve Bank of Cleveland (April 1, 1995).

Crawford, Allan, and Alan Harrison. "Testing for Downward Rigidity in Nominal Wage Rates," Price Stability, Inflation Targets and Monetary Policy, Bank of Canada (1997), pp. 179-218.

Fama, Eugene, and Michael Gibbons. "A Comparison of Inflation Forecasts," Joumal of Monetary Economics 13 (May 1984), pp. $327-48$.

Gastwirth, Joseph. "On the Sign Test for Symmetry." Joumal of the American Statistical Association 66 (December 1971), pp. 821-23.

Gupta, Milan K. "An Asymptotically Nonparametric Test of Symmetry." Annals of Mathematical Statistics 38 (1967), pp. 849-66.

Hotelling, Harold, and Leonard Solomons. "The Limits of a Measure of Skewness," Annals of Mathematical Statistics 3 (1932), pp. 141-42.

Kahn, Shulamit. "Evidence of Nominal Wage Stickiness from Microdata," American Economic Review 87 (December 1997), pp. 993-1008.

Lebow, David, David Stockton, and William Wascher. "Inflation, Nominal Wage Rigidity, and the Efficiency of Labor Markets," Board of Govemors of the Federal Reserve System, Finance and Economics Discussion Series: 94-45, (October 1995). 


\section{REVIEW \\ MAY / JUNE 1999}

Mclaughlin, Kenneth. "Rigid Wages?" Journal of Monetary Economics 34 (December 1994), pp. 383-414.

Changes." Manuscript, (1999)

. "Testing for Asymmetry in the Distribution of Wage

Mood, Alexander, Franklin Graybill, and Duane Boes. Introduction to the Theory of Statistics, 3rd ed, McGraw-Hill, New York, 1974.

Pearce, Douglas. "Comparing Survey and Rational Measures of Expected Inflation: Forecast Performance and Interest Rate Effects," Joumal of Money, Credit, and Banking 11 (November 1979), pp. 447-56.

Shea, John. "Comment," In Reducing Inflation: Motivation and Strategy, Christina Romer and David Romer eds. National Bureau of Economic Research Studies in Business Cycles, v. 30, University of Chicago Press, 1997, pp. 114-121.

Startz, Richard. "Discussion of 'Are Nominal Wage Changes Skewed Away From Wage Cuts?"" This Review, this issue.

Weiss, Andrew, and Henry Landau. "Mobility and Wages," Economics Letters 1,5 (1984), pp. 97-102. 